\title{
Metateorización interdisciplinaria para Noticia de un secuestro (1996): Literatura y Criminología.
}

Interdisciplinary Metatheorizing for News of a Kidnapping (1996): Literature and Criminology.

DOI: 10.32870/sincronia.axxv.n79.20a21

\author{
Jesús Miguel Delgado Del Aguila \\ Universidad Nacional Mayor de San Marcos (PERÚ) \\ CE: tarmangani2088@outlook.com / ID ORDID: 0000-0002-2633-8101
}

Esta obra está bajo una Licencia Creative Commons Atribución-NoComercial 4.0 Internacional

Recibido: 30/09/2020

Revisado: 03/10/2020

Aprobado: $17 / 11 / 2020$

\section{RESUMEN}

Para la construcción teórica que permitirá el análisis de Noticia de un secuestro (1996), me baso en el establecimiento del carácter sociológico que poseen las disciplinas de la Literatura y la Criminología (la manera de organizar la sociedad, mediante determinadas leyes y normas), además de poseer otras similitudes (dimensiones artística, interpretativa y escrita), tal como las señala Pérez (2006). El modo de articular estas propuestas resulta algo problemático, pues no hay un nexo interdisciplinario que esté total e intelectualmente elaborado, según lo sostienen Nelson, Treichler y Grossberg: dificultad que no permitiría contextualizar, teorizar y cuestionar las bases con las que se trabajan. Por tal motivo, los Estudios Culturales tienen una funcionalidad necesaria: su metodología no cuenta con garantías sobre el privilegio que se les otorga a las estructuras internas de lo interdisciplinario. Para ello, he desarrollado dos orientaciones que explican ese fenómeno: los abordajes literario y criminológico. 
Palabras Clave: Estudios Culturales. Criminología. Literatura. Política criminológica. Estado nación.

\section{ABSTRACT}

For the theoretical construction that will allow the analysis to News of a Kidnapping (1996), I rely on the establishment of the sociological character of the disciplines of Literature and Criminology (the way of organizing society, through certain laws and regulations), besides having other similarities (artistic, interpretative and written dimensions), as pointed out by Perez (2006). The way of articulating these proposals is somewhat problematic, because there is no interdisciplinary link that is fully and intellectually elaborated, according to Nelson, Treichler and Grossberg: difficulty that would not allow contextualizing, theorizing and questioning the bases with which we work. For this reason, Cultural Studies would have a necessary functionality: its methodology does not have guarantees on the privilege that is granted to the internal structures of the interdisciplinary. For this, I have developed two guidelines by which that phenomenon could be explained: the literary and criminological approaches.

Keywords: Cultural Studies. Criminology. Literature. Criminological policy. Nation State.

\section{Introducción}

El tratamiento basado en la Literatura posee un rol primordial, ya que se toma como objeto de estudio una obra literaria, a la vez, se relacionan formulaciones de estructuración, que facilitan la fundamentación acerca de los temas y la composición de escenas y personajes de la novela, con la finalidad de enlazar, interdisciplinariamente, conceptos criminológicos y justificar la ausencia de un Estado nación en Colombia. Por ejemplo, el personaje criminal de Noticia de un secuestro (1996) es prioritario en esta investigación, puesto que, una vez configurado, se tiene una concepción más detallada de los procesos sociales existentes durante ese periodo macrocriminal expuesto en esta obra literaria. 
El segundo tratamiento, el criminológico, se refiere, según Burgos Mata $(1994$, p. 46) a algunas ciencias sociales, como la Antropología, la Sociología y la Psicología Criminal, entre otras: siempre y cuando, ayuden al engrandecimiento del objeto. Por otro lado, en la Criminología, se considera la importancia de la tríada criminal a través de los siguientes componentes: el delito, la víctima y el victimario, aunque se puede añadir, también, la acción del entorno social como control formal e informal, según el criterio de Norza Céspedes y Espino-Duque (2011, p. 153). Asimismo, tiene por objeto de estudio las conductas antisociales, las cuales atentan contra el bien común (la ley que rige a la comunidad y es bien para todos) y provocan delitos (Rodríguez, 1981, p. 21). Por eso, hay una recurrencia necesaria en el Derecho Penal de poseer un conjunto de normas y disposiciones jurídicas que regula el ejercicio del poder sancionador y preventivo del Estado (Jiménez, 2005, p. 18).

\section{Conexión interdisciplinaria entre Criminología y Literatura (Estudios Culturales)}

Los Estudios Culturales se producen como una respuesta al proceso de disciplinarización (y disciplinamiento) del saber; es decir, se articula un orden obligatorio en la investigación, una arqueología del saber, y es a partir de ese instante en el que el conocimiento tiene la posibilidad de proliferarse. No obstante, este proceso de esquematizar y regularizar los sucesos se reconoce como habitus, que es el resultado puro, implícito, organizado y posicionado, que se ha obtenido a través de la cultura de cada intérprete. Literariamente, para Pierre Bourdieu (1997, p. 19), este concepto significa lo siguiente: es un cuerpo socializado y estructurado por la percepción y la acción de este mundo. Sobre esa base, se empieza a inferir una organización en función del tema de investigación. Por otra parte, debe tenerse en cuenta que me he referido al habitus ${ }^{1}$, solo para explicar cómo se

\footnotetext{
${ }^{1}$ El habitus: término que emplea Pierre Bourdieu (1997) para aludir a las disposiciones, las estructuras organizativas del ser social o sus esquemas interiorizados, que permiten tomar posiciones y elecciones en los ámbitos más diferentes de la práctica (sociales, simbólicos e ideológicos). Foucault (2004, p. 173) sostiene que a través de la liberación de una estructura pura e implícita se manifiesta la verdad, la arqueología que se forma luego de distintas transformaciones, con intención de elaborar configuraciones singulares en las acciones y las ideologías, similar a la performance, que Antonio Prieto Stambaugh (Szurmuk \& Mckee, 2009, p. 207) define como un paradigma analítico que produce la aproximación hacia procesos comunicativos mediante actividades expresivas, las cuales se articulan con lo interdisciplinario. Por tal
} 
abordará el trabajo de investigación, el cual se somete a una operación autónoma e independiente del área literaria.

Para constituir este concepto organizativo, es necesario iniciar con lo que se desea configurar: en este caso, la realidad. Esta empieza a construirse en relación con el lenguaje y su sociedad. De igual manera, se califica en torno a una estructura espacial que ordena todos sus niveles, como lo social y lo jerárquico que establece un Gobierno durante un periodo macrocriminal. Una vez abstraída la sociedad, se infiere el tipo de cultura que se desarrolla. Por ello, es de importancia esta exposición colectiva para Doležel (1999, pp. 153-154), puesto que son fundamentales para otorgarle lógica y desenvolvimiento a los grupos sociales; en consecuencia, la formación de un Estado nación.

Específicamente, es importante haber optado por una organización convencional desde los Estudios Culturales, debido a que se infiere el siguiente fenómeno: en la actualidad, se percata un problema consuetudinario en los noticieros colombianos nacionales RCN Noticias, Noticias Uno, CM\&, Telepaís y Noticia Caracol, igualmente que en la prensa escrita, como El Tiempo, El Espectador, La República, El Colombiano, El Mundo, El Heraldo, El Universal, Diario del Sur, La Opinión, El País, entre otros, que cuentan con la misma finalidad. Esa intención consiste en difundir la realidad de los hechos acaecidos en el mundo. También, si se asume lo ocurrido solo en Colombia, basándose en el tópico criminológico, se hallan los siguientes noticieros: "9 muertos en Bogotá tras celebración del partido de Colombia” (2014)², "Suman 33 niños muertos por tragedia en Colombia" (2014)33, "Uno de cada 30 asesinatos en el mundo ocurre en Colombia" (2014)4. Se deduce que todavía persiste la difusión del perfil del criminal en acción. Esta información data del año 2014. Por lo tanto, se observa una secuencia de desenvolvimientos criminales, que ya tiene un

motivo, el habitus es una base para generar una metateoría entre la Literatura y la Criminología. Por ejemplo, en la clasificación de agentes que luchan contra el orden y de quienes lo protegen. A la vez, todo ello provoca una interpretación más amplia de Noticia de un secuestro (1996).

${ }^{2}$ Véase el diario Noticias RCN, desde el siguiente enlace: https://bit.ly/1p7KHQO, publicado el 15 de junio del 2014.

${ }^{3}$ Cf. Unión Visión Noticias (2014), publicado el 27 de mayo, mediante la siguiente dirección: https://bit.ly/2NIOxaf

4 Tómese como referencia el diario El Tiempo, a través del enlace siguiente: http://www.eltiempo.com/noticias/muertes-violentas, publicado el 20 de abril del 2014. 
antecedente histórico remitente (un periodo macrocriminal, con respecto al narcoterrorismo infundido por Pablo Escobar). En suma, toda esta materia sirve para incentivar la creación literaria. Con el énfasis en los tipos de crímenes (obviando la novela Noticia de un secuestro [1996]), se hallan obras literarias colombianas recientes que reinciden con la misma temática: La Virgen de los sicarios (1993) de Fernando Vallejo, Rosario Tijeras (1999) de Jorge Franco Ramos, El hombre de los mil nombres (2006) de Ricardo Silva Romero, Relato de un asesino (2001) de Mario Mendoza, Demasiados héroes (2009) de Laura Restrepo, 35 muertos (2011) de Sergio Álvarez Guarín, La serpiente sin ojos (2012) de William Ospina, El sastre de las sombras (2013) de Rubén Varona, Maldad. La sangre de los condenados (2013) de Germán Camacho López, Ximénez (2013) de Andrés Ospina, entre muchas otras novelas que mantienen la misma temática y que, incluso, siguen produciéndose hasta estos momentos. Sobre la base de ello, el problema surge al formularse las siguientes preguntas: ¿es válido el estudio que se hace en las novelas de violencia sociopolítica sin tomar referencias criminológicas o jurídicas? ¿Hasta qué instancia puede considerarse la teoría literaria para el análisis de los textos con temáticas criminológicas? Para direccionar esta idea de modo adecuado, se abordarán tópicos en común, en los que las disciplinas de la Criminología y la Literatura intervengan. Verbigracia, de lo literario, se halla el análisis textual que se hace en Noticia de un secuestro (1996), por el hecho de identificar textualmente la configuración de los personajes (forma de pensar o ideología, manera de comunicarse y actuar; a su vez, la intervención de la pragmática y la semiótica).

No hay teorías exclusivas y universales para referirse al Derecho o la Criminología desde la Literatura, y viceversa: la relación tan solo es bidireccional (de intercambio); es decir, sus técnicas de análisis son independientes y autónomas. No obstante, el incipiente paradigma de los Estudios Culturales ha establecido un lazo antropológico comunicante, con el fin de hallar y comprender algunos fenómenos y algunas conexiones, que permiten la generalidad o la ortodoxia interdisciplinaria, que anteriormente no eran accesibles a través de las áreas independientes y autónomas existentes. La solución no es simple, tal como la plantea Carlos Reynoso (2000, p. 37), basado en Nelson (1992), puesto que los Estudios Culturales no son una disciplina académica; 
tampoco, están ni total ni intelectualmente trabajados. Las citas teóricas explican una particularidad de que se presenta un problema disciplinario, no desde otro campo.

El discurso es insuficiente para instaurar alguna disciplina ajena desde otro dominio. De igual modo, las referencias aludidas que argumenten un fenómeno histórico, económico o político, como se suele hacer desde un área en específica, son cuestionables. Por tal motivo, no tienen una metodología propia: no poseen sus distintivas fórmulas estadísticas, teóricas, sociológicas, académicas, políticas, etnológicas o textuales. Aplican una metodología ambigua, fundamentada en una investigación dependiente de las preguntas y contextualizada en función de las respuestas, sin considerar que entre ellas una sea más importante que otra, ni teniendo en cuenta si la manera como ha sido contestada es correlativa con ese contexto. En consecuencia, no hay prerrogativas ni garantías de privilegiar una metodología única. ¿A qué lector le gustaría adquirir un texto de esta naturaleza? Peor aún, ¿qué institución divulgaría esta producción en el mercado?

En palabras de Richard Johnson (1997) $)^{5}$, los Estudios Culturales necesitan ser inventados: ni siquiera otra disciplina se encargará de proponer vínculos interdisciplinarios (ni la crítica literaria, ni la sociología, ni ninguna otra disciplina académica servirán tan bien para cuestionar esta conexión). Néstor García Canclini (1997, p. 5) admite que, para que la construcción interdisciplinaria sea válida y universal, se cumplen los siguientes requisitos: contar con unos enunciados coherentes y ser pertinentes para su contrastación empírica (lo nacional contra lo global, lo hegemónico multicultural en oposición a lo minoritario, etc.), a la vez, revelarán lógicas y estrategias diferentes para acceder a lo real y validar sus conocimientos. Sin embargo, como también se quiere conocer la cultura, el énfasis de la investigación debe enfocarse no preferencialmente en las identidades parciales (metrópolis, naciones periféricas o poscoloniales, élites, grupos subalternos, disciplinas aisladas), sino en la aprehensión de las intersecciones (García, 1997, p. 8). En otras palabras, de todo lo que permite la interculturalidad o lo interdisciplinario, ¿cuáles son sus semejanzas y sus diferencias? ¿Cuáles son las intersecciones culturales que aluden al "entre lugar"? Si las propuestas

\footnotetext{
${ }^{5}$ Citado por Carlos Reynoso (2000, p. 26). Apogeo y decadencia de los Estudios Culturales. Una visión antropológica. Recuperado de https://bit.ly/2Lmdtjf
} 
de formulación son compatibles con esos requisitos, es decir, si la "perspectiva sociocultural" ${ }^{6}$ ha cumplido su objetivo, entonces, se ha logrado construir un lenguaje propio o un nuevo lenguaje, que verterá la unión exitosa entre Literatura y Criminología, caracterizada no por ser técnica, aunque sí social.

El aprendizaje de la Literatura por sí solo facilita una nueva y mejor utilización en el discurso de lo jurídico. De la misma forma, es útil si se estudia Derecho para la aplicación de la Literatura. A partir de allí, se trata el forjamiento de un espacio crítico (Karam y Magalhães, 2009, p. 166), en el que se puedan cuestionar presupuestos, fundamentos, legitimidades, funcionamientos, etc.

Un tema que se ha abordado desde los Estudios Culturales es el mencionado en el desarrollo del párrafo anterior: lo interdisciplinario. El criminólogo Luis Rodríguez Manzanera (1981, pp. 39-40) se refiere a este término como la dependencia mutua existente entre las ciencias y las disciplinas con las que se frecuentan, con la intención de complementar, coordinar, integrar y explicar desde cualquier perspectiva; todo ello con un mejor enfoque que el de lo multidisciplinario (en el que predominan la cantidad y la reducida regulación temática, debido a la intervención de muchas disciplinas) ${ }^{7}$.

A continuación, es necesario especificar una indagación reiterativa: así como los Estudios Culturales, la Teoría Literaria, las Literaturas Comparadas, los Estudios Poscoloniales, entre otras vertientes, se fundamentan de su área general, Literatura, sucederá lo mismo con la Criminología, la cual se basa en un todo, que es el Derecho. Por eso, he visto necesario hacer una comparación panorámica y válida, bajo los parámetros justificativos (en cuanto metodología de investigación, explicados en los párrafos anteriores), entre las partes absolutas: la Literatura y el Derecho, sin obviar la Criminología, la cual se abordará en función de tratados comparativos y descriptivos.

\footnotetext{
${ }^{6}$ Rossana Reguillo en su artículo "Los Estudios Culturales. El mapa incómodo de un relato inconcluso" (2004, p. 9) alude a este término para referirse a todo lo que logra su difusión, como también la modificación de otras culturas, ya sea con nuevas estructuras sociales objetivas, al igual que mencionar procesos simbólicos.

${ }^{7}$ Debe distinguirse también de lo transdisciplinario, que es, bajo el concepto de Rossana Reguillo (2004), un proceso de encuentro cultural, el cual surge a causa de la idea de pensar el mundo y la propia sociedad en condiciones asimétricas de poder. Por ello, los Estudios Culturales son una propuesta intelectual para comprender las intersecciones culturales.
} 
Faustino Martínez Martínez (2005, p. 133) sostiene que la intención de conectar Derecho con Literatura es la de enriquecer la cultura, la cual se manifiesta en múltiples representaciones (valores, principios, deseos y todo componente ético sentimental de una comunidad, un pueblo, un Estado o una nación) que se evidencian a través del lenguaje, el folclore, el derecho, el arte, la literatura, la pintura, las leyendas, etc. Sin embargo, ante esta diversidad de elementos, es complejo e inadecuado articular conceptos de forma independiente de ambas áreas. Por lo tanto, resulta más importante ver esas conexiones que se producen entre ellas. Carlos Pérez (2006, p. 135) hace unas precisiones semánticas de las disciplinas que competen en el siguiente análisis (Derecho y Literatura) para una mejor comprensión, tomando como referencia el Diccionario de la Real Academia Española. Entonces, la terminología de Derecho es el "conjunto de principios y normas, expresivos de una idea de justicia y de orden, que regulan las relaciones humanas en toda sociedad y cuya observancia puede ser impuesta de manera coactiva" (RAE, s.a., párr. 13). Entretanto, la Literatura significa el "arte que emplea como medio de expresión una lengua". En torno a lo constituido, el vínculo surge entre sus naturalezas expresivas (la lengua de la comunidad o la naturaleza lingüística). Igualmente, el mismo autor (Pérez, 2006, p. 139) plantea la existencia de tres dimensiones que explican la conexión entre el Derecho y la Literatura: la artística o literaria, la interpretativa y la escrita.

I. La dimensión artística o literaria. En la literatura, predominan los tópicos o los contenidos del discurso sobre la criminalidad ${ }^{8}$ y el cumplimiento de la ley ${ }^{9}$. Además, el modo como se ha tratado los temas de la muerte, la amenaza, el chantaje, la violación, el secuestro y la

\footnotetext{
${ }^{8}$ Para mencionar algunos casos, recuérdese el tema del asesinato planteado por el escritor ruso Fiódor Dostoievski en su novela Crimen y castigo (1986), como también la novela del norteamericano William Faulkner, Santuario (1931), en la que la violación hecha hacia Temple Drake desvela una tonalidad de maldad y podredumbre de ese tipo de sociedad representada, junto a la novela del peruano Mario Vargas Llosa, La ciudad y los perros (1963), que instiga sobre la problemática de las violencias física y psicológica impartidas por sus personajes, junto con el asesinato al personaje Ricardo Arana (el Esclavo). Diversas instancias de criminalidad están registradas en la literatura mundial.

${ }^{9}$ Un ejemplo se desarrolla en el texto de Mario Vargas Llosa, El sueño del celta (2010), en el que se castiga a Roger Casement con su ejecución, porque ha traicionado al Gobierno inglés con la delación a sus compatriotas por el maltrato y la explotación indígenas y amazónicas de América. Del mismo autor, están sus novelas Pantaleón y las visitadoras (1973), ¿Quién mató a Palomino Molero? (1986), Lituma en los andes (1993) o La fiesta del Chivo (1998), en las que la figura del orden (la Policía, el Ejército y otras instituciones) es cuestionada por delinquir su rol principal.
} 
violencia, en general, han permitido que los géneros literarios estén ligados con la disciplina jurídica. Conexión que es evidente no solo en la Literatura, sino que se aprecia en el cine desde hace muchos años ${ }^{10}$. En cierta parte, la Literatura es una herramienta para el progreso y la imaginación morales, ya que produce en los lectores mayor sensibilidad acerca de sus necesidades y las diferencias de las personas (Vásquez, 2006, p. 175).

II. La dimensión interpretativa. De acuerdo con Levinson y Mailloux, la alusión a las técnicas hermenéuticas (como las de Bajtín, Ricoeur o Gadamer), es impulsada y desarrollada ampliamente para una mejoría de la interpretación dentro de los estudios literarios. Este tipo de investigación y aporte ha sido aprovechado por el Derecho, tal como lo ha demostrado Carlos Pérez (2006, p. 141) al referirse a Paul Ricoeur, quien menciona que la interpretación es producto de un proceso permanente y dinámico, propio para ejercer el Derecho, disciplina humana que se expresa por escrito. También, está la propuesta hecha en conjunto por André Karam Trindade y Roberta Magalhães Gubert (2009, p. 170), en la que se argumenta que la Literatura cumple la función de vehículo de creatividad en el Derecho, puesto que esta ayuda a los juristas a construir soluciones y abordar con mayor exactitud su interpretación. Al respecto, Stanley Fish reflexiona sobre la conexión discursiva entre lo literario y lo jurídico:

En la actualidad, la teoría ha alcanzado un protagonismo notable en unos campos donde el interés común por los textos constituye un importante punto de unión. Tanto los profesores de Derecho como los de literatura no dudan en buscar claves hermenéuticas en la otra disciplina. Incluso algunos profesores de Derecho ven en la literatura la posibilidad de escapar de un futuro tecnocrático. Mientras que según algunos profesores de literatura, el Derecho les rescataría de la marginación (Fish, 1986, p. 654).

III. La dimensión escrita. El relato de los hechos tiene dos funciones. La primera de ellas es captar la atención de los sucesos y sugestionar al lector y el juez (o jurado) (Calvo, 2007, p.

${ }^{10}$ Películas que abordan ese tema son innumerables. Algunas son El candidato manchuriano (1962), La vida es bella (1997), La boca del lobo (1988), La última llamada (2003), entre otras más. 
12). No obstante, también, implica que ambas disciplinas se desarrollen en fuentes materiales escritas (leyes, documentos, novelas, poemarios, Constituciones, etc.). Por ejemplo, en la actualidad, Colombia cuenta con editoriales tradicionales (textos elaborados y distribuidos desde las mismas imprentas) y virtuales (textos que son escaneados, reeditados o creados desde la internet). Algunas de estas son Diente de León, Produmedios, Editorial D’Artagnan, Rey Naranjo Editores, Continente Editores, EB Ediciones EU, Lemoine Editores, Icono Editorial, Editorial Robot, Encuadernación Colombia, Biblomedia Editores, Pedagogía Vial, Siglo del Hombre Editores, Panamericana Editorial, Editorial Babilonia, etc. Sin embargo, no es solo su difusión con fines publicitarios, sino que además se emplea, en ambos casos, como un proceso o una representación de la misma disciplina: juicios orales o declaraciones son transcritos y usados como manifestaciones del acusado y el acusador. En el ámbito literario, ocurre igual, la literatura oral o colectiva es transferida a una literatura escrita, como sucede con el género épico; verbigracia, la Ilíada (ss. VIII-VI a. C.), la Odisea (s. VIII a. C.) o El cantar del mío Cid (1195-1207).

A partir de estas dimensiones, puede optarse por otros vínculos configuradores entre ambas disciplinas, como al mencionar que las dos tienen como ejes categorías y principios que permiten revelar la cultura de la sociedad y plantear su propia organización a través de leyes, tensiones, luchas, conflictos sociales, políticas, religiones, economías o normas jurídicas establecidas que se cumplen en un determinado medio. Por ejemplo, Faustino Martínez Martínez (2005) sostiene que la Literatura es solo una representación sociológica que enfatiza la construcción (postula una imagen artificial, como parte de la creación, pero profundamente humana); mientras que el Derecho no puede captar o aprehender toda la realidad, ya que muchos aspectos permanecen invisibles, aunque se vale de ellos igualmente (Martínez, 2005, p. 136). Un aporte más sobre los canales interdisciplinarios es que, si en Literatura hay un espacio para referirse a lo interdisciplinario desde los Estudios Culturales (Literatura-Derecho), ya sea como asignatura del pregrado o programa del posgrado (maestría o doctorado), en Derecho también se genera un canal al aludir a la conexión 
literaria, con Filosofía del Derecho (Lorca, 2012, p. 121), de la cual existen cursos y programas de posgrado, como la que hay actualmente en la Facultad de Filosofía de la Universidad Libre (Bogotá) con la maestría en Filosofía del Derecho y Teoría Jurídica, a la que postulan alumnos de Sociales, Filosofía y Derecho.

Debido a que se conocen los vínculos (semejanzas y diferencias) interdisciplinarios entre Derecho y Literatura, planteo los fines que tienen, desde una perspectiva independiente y autónoma, tomando como fundamento el trabajo realizado por Faustino Martínez Martínez: "Derecho común y Literatura: dos ejemplos de los siglos XVI y XVII" (2005). Para ello, inicio con las intenciones primordiales de un texto literario. Desde la narratología, se asume que la novela es tan solo un objeto estético; es decir, que posee sus propias licencias estilísticas, con el uso de una retórica variante y una ideología destacable, de las que la crítica literaria (lectores-intérpretes) puede inferir diversidad de interpretaciones sobre estas o en función de la sociedad imperante, ya sea con descripciones o críticas. Al respecto, Marcel Proust afirmaba que cada lector es lector de sí mismo. Por lo tanto, la interpretación de la sociedad se genera de forma desigual, dependiendo del nivel cultural de cada uno (Martínez, 2005, p. 136).

Ahora, en relación con el Derecho, se emplea una retórica discursiva autónoma y su finalidad es la de ejercer el poder social como autorización (se complementa con diversas perspectivas, verdades y certezas relativas: no es autónoma). En consecuencia, cualquier imprecisión semántica desde esa instancia es perjudicial para el dogma de la plenitud del ordenamiento (Carreras, 1996, p. 4); es decir, la Literatura es más subjetiva: admite diversidad de criterios, puesto que no hay una sola verdad, ni tampoco un modelo absoluto y mejor; mientras que el Derecho es de carácter objetivo: una mala interpretación, algo infundado o una mentira provoca un mal resultado, el cual es sentenciado y penado, según sea la gravedad, ya que hay textos obligatorios e invariables como las leyes y las Constituciones para su argumentación.

Ahora que ya se tienen en consideración los fines de la Literatura y el Derecho, se puede cuestionar la intención de Noticia de un secuestro (1996), que es el producto o la interrelación entre ambas disciplinas. Primero, se halla el afán expositivo de un periodo macrocriminal, tomando en 
cuenta que en la novela de Gabriel García Márquez se abarca un contexto específico: el narcoterrorismo en Colombia a fines del siglo XX. Segundo, se encuentra la idea de elogiar la figura del criminal a través de lo literario: se exaltan a los personajes de Pablo Escobar y todos los que cumplen un rol criminal (representan un emblema social), como los secuestradores, los extorsionadores y los homicidas presentes en el texto (el control ideológico forma parte de muchas lecturas de las clases populares, sin que sean solo puntos de apoyo sino temas de interés político). Tercero, está la búsqueda de un estereotipo legal o la ejecución de una práctica penal: la manifestación de personajes que son figuras de autoridad que se desenvuelven en aspectos actanciales (el rol de los policías y los gobernantes frente al crimen) y discursivos (la expresión verbal, tanto oral como escrita, inserta un eje de dominación y regimiento a la sociedad colombiana). Estas son algunas propuestas que se destacan desde lo interdisciplinario, las cuales se complementan con las aproximaciones de los Estudios Culturales, la Criminología y el término empleado por Pierre Bourdieu, el habitus.

\section{Orientación criminológica}

Desde la concepción de Luis Rodríguez Manzanera (1981, p. 92), la Criminología es dinámica, evoluciona. Esta surge del positivismo, ya que se basa mucho en la claridad y la consistencia, propias de las ciencias naturales. Específicamente, aborda la personalidad del delincuente y su peligrosidad social. Además, tiene como finalidad investigar acerca de las conductas antisociales, que obstaculizan o perturban el bien común: muy distinto del delito, que alude a infringir una ley establecida, mediante una acción o una omisión castigables por las Leyes Penales. Por otro lado, esta disciplina busca superar el Estado liberal no intervencionista, como también, la individualización de la pena, de acuerdo con la peligrosidad del criminal (características biológicas, antropológicas y psicológicas) (González-Gómez y González-Chávez, 2007, p. 168).

Para este análisis, he obviado una subárea de lo antropológico: lo que César Lombroso (1835-1909) define como antropología criminal, basada en la transposición directa de la anatomía al psiquismo y el comportamiento, por la que el delincuente se llega a fundamentar desde lo 
ahistórico y lo apolítico (fenómeno patológico, que retoma la negación del libre albedrío y necesita de apoyo colectivo para contrarrestarlo). En otras palabras, consiste en un producto natural y no el resultado de un proceso político-cultural. Verbigracia, un individuo presenta síntomas criminológicos por su malformación en el occipital izquierdo. Todo ello requiere la psiquiatría y la antropología criminal (González-Gómez y González-Chávez, 2007, p. 168), ya que el interés recae sobre el victimario, no en el delito.

Aparte de lo expuesto, señalo definiciones pertinentes de Criminología (Rodríguez Manzanera, 1981, pp. 3-6), que se considerarán para los estudios posteriores.

I. Ruiz Funes la asume como una ciencia sintética y empírica, que cuenta con sus límites establecidos según su contenido: el estudio triple del delincuente y el delito, en función de aspectos antropológico-biológicos, psicológicos y sociológicos.

II. Rafael Garófalo la define como la ciencia del delito. Para ello, diferencia el "delito sociológico o natural" (al que designa igualmente "crimen") del "delito jurídico" (el atribuido por el legislador en el Código Penal).

III. Don Constancio Bernaldo de Quirós conceptualiza la Criminología como la ciencia que se ocupa de estudiar al criminal en todos sus aspectos. Si se hace referencia a la ciencia del delito, se denomina Derecho Penal (por ejemplo, el narcotráfico, el secuestro, la extorsión, el asesinato, el chantaje, la violación a las leyes, etc.). Si hay alusión a la ciencia del delincuente, Criminología (el modus operandi del Cartel de Medellín, los Extraditables o el desempeño de Pablo Escobar sobre el Gobierno colombiano). Si se está considerando la ciencia de la pena, Penología (la extradición que está en los Decretos 2047/1990 y 3030/1990 del Gobierno de Colombia de Noticia de un secuestro).

En la Criminología, se usan cuatro conceptos operacionales (Rodríguez Manzanera, 1981, p. 27): la causa, el factor, el móvil y el factor causal.

I. La causa. Es notoria en el desarrollo de una condición necesaria e indispensable para la manifestación de un comportamiento. Verbigracia, el secuestro de personajes como Maruja 
Pachón de Villamizar, Beatriz Villamizar, Francisco Santos, Marina Montoya, Diana Turbay, entre otros, corresponde a una insatisfacción por parte del Cartel de Medellín al negarse César Gaviria de modificar los Decretos 2047/1990 y 3030/1990, en los que designaba una severa sanción a quienes infringieran la ley mediante la extradición en EE. UU. Algo importante, en función de la definición de causa, es que esta se desenvuelve de forma cohesiva y constante: se halla conectada con otros sucesos generados. Es unívoca y de carácter genético entre acontecimientos naturales, ya que un suceso suscita otro. Del caso anterior, los secuestros provocarán rebeldía, negociaciones, asesinatos, otros posibles secuestros, extorsiones, etc.: no hay manera de reducir ni alterar la dinámica.

II. El factor. Favorece el fenómeno criminal. Por ejemplo, el alcoholismo, la promiscuidad, las alteraciones fisiológicas, pueden ser factores criminógenos. Los Extraditables emplean las violencias psicológica y física, junto con la extorsión garantizada con armas.

III. El móvil. Se trata del elemento subjetivo que lleva a un sujeto en particular a realizar una conducta antisocial. En relación con el texto de Gabriel García Márquez, este móvil es identificable por medio de un diálogo que presenta interrupciones y poca claridad, puesto que este se fundamenta a través de chantajes, amenazas o extorsiones, lo que produce que el Gobierno colombiano se adapte a las exigencias de los Extraditables.

IV. El factor causal. Es quien se encarga de cometer un acto criminal, partiendo de un referente o un modelo. Al respecto, el inicio de la novela muestra una escena criminológica, un acto de secuestro, el cual es reconocido por los personajes, como también por el lector. Esta secuencia es identificable, puesto que para los criminales las víctimas son una garantía reforzada de que las entidades del poder político deben adaptarse, con mayor presión, a sus exigencias.

A causa de que ya se cuentan con las nociones básicas de la Criminología argumentadas, definidas tan solo con un fin contextual y de aproximación, sin cuestionar sus planteamientos, haré el vínculo mediante el propósito de los Estudios Culturales; es decir, la conexión interdisciplinaria 
para precisar sobre los temas que se analizarán en Noticia de un secuestro (García, 1996). En algún momento, este modo de investigar lo fundamentó Burgos Mata (1994, p. 46), al plantear que, para el estudio de la Criminología, se necesita como referencia el contacto con algunas ciencias sociales, como la Antropología, la Sociología y la Psicología Criminal, entre otras; siempre y cuando, ayuden al crecimiento del objeto. Recuérdese que la Criminología se enfoca en la tríada criminal de delito, víctima y victimario. A su vez, se añade la acción del entorno social como control formal e informal. Al respecto, se tiene por objeto de estudio las conductas antisociales, que atentan contra el bien común (la ley que rige a la comunidad y es bien para todos), que pueden generar delitos. Por eso, hay una recurrencia necesaria en el Derecho Penal de poseer un conjunto de normas y disposiciones jurídicas que regule el ejercicio del poder sancionador y preventivo del Estado.

En relación con la Criminología, retomo dos terminologías: la víctima y la política criminológica (métodos de prevención social).

I. La víctima. Se le atribuye esta definición a la persona que padece un daño físico y psicológico, además de estar expuesta a una situación de riesgo delictivo: esto es propicio desde un ámbito social o político. Por otro lado, un área mayor, especializada en los agredidos por estas causas, es la Victimología. En esta novela, se asume tal atribución a los personajes que fueron secuestrados y violentados por el Cartel de Medellín (verbigracia, la hija del presidente), como también los involucrados directa e indirectamente por los espacios geográfico (ciudadanía colombiana) y político (periodistas).

II. La política criminológica (métodos de prevención social). Prevenir es conocer un daño o un perjuicio. Para su efectividad, se recurre a la elaboración de proyectos de ley, reglamentos, normas y procedimientos vinculados con la política antidelictiva, según las necesidades del caso. En Latinoamérica, no hay un plan bien definido de prevención (Rodríguez, 1981, p. 130). Asimismo, el delito no desaparecerá, pero sí puede transformarse. Con esta designación, Del Rosal Blasco (2009, p. 29) hace mención de la modalidad que busca anular o minimizar las acciones que ejerce un sujeto de riesgo ante la sociedad. Esto es posible, siempre y cuando, si es que se instituye en el país (Colombia) un Derecho Penal 
que sirva como un subsistema excesivamente estático del control social (con la protección de los bienes jurídicos). Sin embargo, eso no se desarrolla por el hecho de que los referentes sociales y políticos estén dañados: una muestra de ello es que se cuestionan las bases económicas y culturales (pensamiento capitalista del marxismo-leninismo), debido a que la macrocriminalidad ha estado presente para interrumpir el progreso, la democracia, la soberanía y la organización de un código jurídico centrado. Para la orientación de este tópico social, hay una clasificación en cuatro sectores: la intervención de entidades militares, la función policial, las leyes jurídicas y la prisión como método correctivo.

La primera es la intervención de entidades militares. En muchas instancias, la forma de legislar la sociedad por parte de los militares, al igual que de los policías, es de una manera violenta, aunque justificada con fines progresistas. Ante ello, se ha intentado plasmar una lógica democratizadora. No obstante, los índices de corrupción y violación a los derechos humanos son causados por el mismo personal de defensa. Por lo tanto, implica que, al aludir al enemigo, se establezca otra serie de pacto económico y político.

La segunda se trata de la función policial en la seguridad ciudadana y la investigación criminológica. Esta se fundamenta en el ejercicio de una moralidad a través de los agentes del orden, sustentada legislativamente. En Noticia de un secuestro (1996), se observa la importancia de la investigación mediante los policías, como también, de la Criminalística, entendida por Burgos Mata (1994, p. 46) como un método inductivo que busca conseguir resultados útiles. La finalidad de estos recursos es preservar la tranquilidad. Por eso, se demarca cualquier tipo de amenaza, ya sea interno (violencia o corrupción) o externo (narcotráfico, homicidios o secuestros).

La tercera abarca las leyes jurídicas colombianas. Con la idea constructivista de establecer un orden, Villa (1999, pp. 295-296) se enfoca en las teorías jurídicas para reconstruir las normas, los hechos psicosociales y las prácticas. Para Foucault (1979, p. 17), la "regla" y la "justicia" son el placer calculado del encarnizamiento, del que se ve la dinámica de la dominación, el deseo de paz y la aceptación tácita de la ley: distante de configurarse como la importante conversión moral (es el 


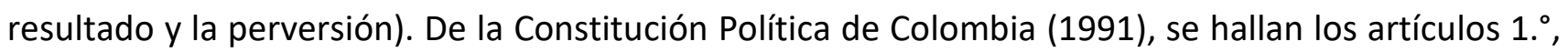
2. $, 11 .^{\circ}, 13 .^{\circ}, 15 .^{\circ}, 16 .^{\circ}, 17 .^{\circ}, 22 .^{\circ}, 28 .^{\circ}, 30 .^{\circ}, 32 .^{\circ}, 44 .^{\circ}, 79 .^{\circ}$ y $87 .^{\circ}$, que establecen a su país como un Estado social de derecho, con su propia autonomía, sus organismos construidos, el respeto a todos los derechos humanos, con igualdad, paz y libertad. Al final de esta obra literaria, este modelo nacional se representa, aunque esa utopía aún requiere material extratextual (el plano jurídico del contexto colombiano coetáneo). Recuérdese que una de las leyes o los tratados firmados por el presidente de Colombia está basado en la extradición a los narcoterroristas. En consecuencia, los miembros del Cartel de Medellín han iniciado una lucha inacabable y tormentosa. Sin embargo, gracias a esta, se ejerce un control sobre lo jurídico en el país.

La cuarta se relaciona con la prisión como castigo o método correctivo y disciplinario. En esta sección, retomo algunos conceptos desarrollados por Luis Rodríguez Manzanera, Michel Foucault, entre otros. Si bien la prisión es una forma de prevenir los abusos y defender a la sociedad por medio del orden, se priva de la libertad al criminal. No solo basta la base legal, sino que se adquiera lo señalado por Foucault:

El castigo disciplinario tiene por función reducir las desviaciones. Debe, por lo tanto, ser esencialmente correctivo. Al lado de los castigos tomados directamente del modelo judicial (multas, látigo, calabozo) [...]. El castigo, en la disciplina, no es sino un elemento de un sistema doble: gratificación-sanción. $Y$ es este sistema el que se vuelve operante en el proceso de encauzamiento de la conducta y de corrección (Foucault, 2003, pp. 166-167).

\section{Conclusión}

Partiendo del concepto de habitus, que fundamenta Pierre Bourdieu, adapté su lógica organizacional para conceptualizar una forma inventada y autónoma de análisis para una novela del posboom, como la del Premio Nobel de Literatura de Colombia, por el hecho de existir elementos multidisciplinarios que poseen intersecciones jurídicas, criminológicas y literarias. Esta particularidad se distancia de una disciplina académica específica. Por lo tanto, los Estudios Culturales sirvieron para validar los planteamientos desarrollados. La lectura de Noticia de un 
secuestro requiere conocimiento extratextual (historia o política colombianas) para comprender la narración periodística y testimonial que usa el escritor: no para buscar una comparación de lo ficticio y lo verídico, sino para tener en cuenta todas las funciones deterioradas que desempeñan los protagonistas de este texto y lograr el respaldo de que efectivamente está ausente el Estado nación en ese periodo macrocriminal de Colombia.

\section{Referencias}

Asamblea Nacional Constituyente (1991). Constitución Política de Colombia. Recuperado de https://bit.ly/2M8bu5W

Bourdieu, P. (1997). Razones prácticas. Sobre la teoría de la acción. Barcelona: Editorial Anagrama.

Burgos, Á. (1994). Criminalística y Criminología. Medicina Legal de Costa Rica, 10-11 (1-2), 45-47.

Calvo, J. (2007). La controversia fáctica. Contribución al estudio de la quaestio facti desde un enfoque narrativista del Derecho. XXI Jornadas de la Asociación Argentina de Filosofía del Derecho. Buenos Aires: Facultad de Derecho, Universidad Nacional de Buenos Aires.

Carreras, M. (1996). Derecho y Literatura. Persona y derecho: Revista de fundamentación de las Instituciones Jurídicas y de Derechos Humanos, 34, 36-62.

Del Rosal, B. (2009). ¿Hacia el Derecho Penal de la postmodernidad? Revista Electrónica de Ciencia Penal y Criminología. Recuperado de http://criminet.ugr.es/recpc/11/recpc11-08.pdf

Doležel, L. (1999). Heterocósmica. Ficción y mundos posibles. Madrid: Arco/Libros.

Foucault, M. (1979). Microfísica del poder. Madrid: Las Ediciones de La Piqueta.

Foucault, M. (2003). Vigilar y castigar. Nacimiento de la prisión. Buenos Aires: Siglo Veintiuno Editores.

Foucault, M. (2004). El nacimiento de la clínica. Una arqueología de la mirada médica. Buenos Aires: Siglo Veintiuno Editores.

García, N. (1997). El malestar en los Estudios Culturales. Fractal, II (6), 45-60.

García, G. (1996). Noticia de un secuestro. Bogotá: Editorial Norma. 
González-Gómez, G. y González-Chávez, M. L. (2007). La teoría criminalística en la individualización de la pena. Cinta Moebio, 29, 167-178.

Jiménez, L. (2005). Principios del Derecho Penal. La Ley y el delito. Buenos Aires: Abeledo-Perrot.

Karam, A. y Magalhães, R. (2009). Derecho y Literatura. Acercamientos y perspectivas para repensar el Derecho. Revista Electrónica del Instituto de Investigaciones "Ambrosio L. Gioja", 4, 164213.

Lorca, M. I. (2012). Derecho y Literatura: género, libertad y justicia en la obra dramática de García Lorca. Revista Prolegómenos, XV (30), 119-140.

Martínez, F. (2005). Derecho común y Literatura: dos ejemplos de los siglos XVI y XVII. Anuario Mexicano de Historia del Derecho, 17, 113-210.

Norza, E. y Espino-Duque, G. (2011). Resultados operacionales de la Policía Nacional, 2010. Criminalidad, 53 (1), 151-163.

Pérez, C. (2006). Derecho y Literatura. Isonomía, 24, 135-153.

Real Academia de la Lengua Española (s.a.) Diccionario de la Real Academia de la Lengua Española. Asociación de Academias de la Lengua Española. https://dle.rae.es/derecho

Reguillo, R. (2004). Los Estudios Culturales. El mapa incómodo de un relato inconcluso. Aula abierta. Lecciones básicas. Barcelona: Portal de la Comunicación.

Reynoso, C. (2000). Apogeo y decadencia de los Estudios Culturales. Una visión antropológica. Recuperado de https://goo.gl/8WBmW9

Rodríguez, L. (1981). Criminología. Ciudad de México: Editorial Porrúa.

Fish, S. (1986). Anti-professionalism. Cardozo Law Review, 7, 89-108.

Szurmuk, M. y Mckee Irwin, R. (Coords.) (2009). Diccionario de Estudios Culturales Latinoamericanos. Ciudad de México: Instituto Mora y Siglo Veintiuno Editores.

Vásquez, A. (2006). Rorty: el giro narrativo de la ética o la filosofía como género literario. Universitas. Revista de Filosofía, Derecho y Política, 3, 173-180.

Villa, V. (1999). Constructivismo y Teoría del Derecho. Doxa, 22, 284-302. 